\title{
The Relationship Between Students' Personality Types and Their Academic Achievement in Oromia Colleges of Teachers' Education
}

\author{
Gadisa Wando Shaka \\ Department of Psychology, Fitche College of Teachers Education, Oromia, Ethiopia \\ Email address: \\ gadisaoda21@gmail.com \\ To cite this article: \\ Gadisa Wando Shaka. The Relationship Between Students' Personality Types and Their Academic Achievement in Oromia Colleges of \\ Teachers' Education. International Journal of Psychological and Brain Sciences. Vol. 5, No. 3, 2020, pp. 47-55. \\ doi: $10.11648 /$ j.ijpbs.20200503.12
}

Received: June 2, 2020; Accepted: June 20, 2020; Published: July 30, 2020

\begin{abstract}
The objective of this study was to determine the relationship between students' personality types and their academic achievement at Oromia Colleges of Teachers' Education. Correlational design was used to conduct the study. The population of the study was 2291 male and 2734 female students in four Oromia Teachers' Education Colleges. 357 students were selected using stratified sampling techniques and followed by simple random sampling method from four randomly selected colleges. The instrument adapted for the study was the 44-item standardized questionnaire known as the Big Five Inventory constructed by John, Donahue, and Kentle as cited in John \& Srivastava (1999). The instrument was piloted before it used for final study and found reliably and valid. The data collected were analyzed using descriptive and inferential statistics. Pearson moment correlation was used to determine the strength of relationship between each personality type and academic achievement. In addition, multiple regressions was used to determine the extent to which the independent variables Agreeableness, Conscientiousness Extraversion, Neuroticism and Open to experience predict the dependent variables grade point average in Oromia Colleges of Teachers' Education. The result of the study show that there was positive significant relationship between students' personality types namely Agreeableness, Conscientiousness and Open to experience and their academic achievement. It was suggested that teachers are expected to identify the personality profiles of their students, to render necessary academic help according to personality nature of students. Oromia Education Bureau is expected to arrange training and seminar, and workshop as well as experience sharing on the issue of students' behaviors in general and personality types in particular. In addition, it is suggested to strength guidance and counseling service in Colleges of Teachers' Education.
\end{abstract}

Keywords: OCEAN, Academic Achievement, Oromia Colleges of Teachers Education, Relationship

\section{Introduction}

Personality as the unique pattern of enduring thought, feelings and action that characterized a person. Personality should not be confused with character, which refers to value judgments made about a person's morals or ethical behavior; nor should it be confused with temperament, the enduring characteristics with which each person is born, such as irritability or adaptability. However, both character and temperament are vital personalities [1]. This means every individual have his/her unique identity that separate from the other but not emanated from societal value and react to a given situation.
Academic achievement is conceptualized as the process in which a learner is profiting from instruction to the extent that skill and knowledge has been imparted as a part of leaning as Crow and Crow cited in [27]. It mean that academic achievement is the educational goal that is achieved by a student, teacher or institution achieves over a certain period and measured either by examinations or continuous assessments and the goal may differ from an individual or institution to another. The dominant measure of academic performance is GPA [23].

Research has mostly focused on factors favoring a high cognitive performance in school. Among such factors the most relevant seem to be the use of learning strategies, 
abilities and metacognition [26].

However researchers have sought to identify non-cognitive predictors of academic achievement, including variables related to personality types. In fact, academic achievement is considered as one important criteria of educational quality. On the other hand, learners are different across a vast range of variables. They differ in terms of personality characteristics, family backgrounds, age and gender, etc., they also exhibit distinctive personality characteristics which makes them prepared for having different worldviews, and thus for behaving differently in various social and educational settings. Considering these differences can help educators recognize their students' individual differences. Predictors of academic achievement often lay on a continuum with cognitive measures, intelligence and mental abilities at one extreme and non-cognitive variable such as personality characteristics, socioeconomic status, etc. at the other one. Educators have always asked whether people's personality characteristics can help them attain higher academic achievement.

Accordingly, the most recent theoretical approach to study personality types and academic achievement based on the Big Five of personality traits [8]. Even though there are different personality types the present study is focused on the relationship between Big Five personality types and student's academic achievement. Many scholars have accepted fivefactor model of personality as a replicable and unifying taxonomy of personality $[10,13]$. Thus, Big 5 personality factors are: Neuroticism, Extraversion, Open to Experience, Agreeableness and Conscientiousness.

\subsection{Research Questions}

Thus, in examining the correlation existing between and among the variables, this study was answered the following research questions.

1. What types of relationship do exist between students' personality type and their academic achievement in Oromia Colleges of Teacher's Education?

2. Which personality types do significantly predict academic achievement of students in

Oromia Colleges of Teacher's Education?

\subsection{Objectives of the Study}

The main objective of this study was to measure the relationship between students' personality types and their academic achievement in Oromia Colleges of Teachers' Education.

Particularly, the study has the following specific objectives:

1. To examine the degree of relationship between students' personality types and their academic achievement in Oromia Colleges of Teachers' Education.

2. To identify the types of personality those predict academic achievement among students in Oromia Colleges of Teachers' Education.

\subsection{Significance of the Study}

The study was identified personality types of students' that contributed to their academic achievement in Oromia Colleges of Teachers' Education. The outcome of this study is significant to:

1) The study may inform the principals and teachers in the area of counseling they expected to provide for students.

2) The study also important for students of colleges that to identify the type of personality they have in order to improve their personality types not only for their academic success but also for their social life in society while implication of the study while apply by colleges dean, teachers and other else.

3) The concerned bodies which are accountable for colleges of Teachers Education in Oromia National Regional State (Oromia Education Bureau) in order to assigned expert of psychology in school for quality education that expressed by academic achievement of students, the outcome of this research serves as input for allocation of budget and preparing seminars, workshop and training in the area of factors that affected students' academic achievement especially the Big 5 personality factors.

4) Serve as stone steps for other researchers.

\subsection{Abbreviations}

$\begin{array}{ll}\text { A } & \text { Agreeableness } \\ \text { AA } & \text { Academic Achievement } \\ \text { ATEC } & \text { Adola Teachers' Education College } \\ \text { CTE } & \text { College of Teachers Education } \\ \text { C } & \text { Conscientiousness } \\ \text { E } & \text { Extraversion } \\ \text { FTEC } & \text { Fiche Teachers' Education College } \\ \text { GPA } & \text { Grade point Average } \\ \text { N } & \text { Neuroticism } \\ \text { NTEC } & \text { Nekemte Teachers' Education College } \\ \text { OCEAN } & \text { Open to Experience, Conscientiousness, } \\ \text { O } & \text { Extraversion, Agreeableness, Neuroticism } \\ \text { SSNEC } & \text { Open to experience } \\ \text { SPSS } & \text { Sebeta Special Need Education College } \\ & \text { Statistical Package for Social Science }\end{array}$

\section{Review of Related Literature}

\subsection{Concept of the Big Five Personality Types}

The history of the trait theory of personality has come through different stages like that of Gordon Allport, Raymond Cattell and Hans Eysenck and lastly psychologist agreed on the big five personality types though; our attention here will be paid on the five-factor model or the Big Five theory. The five trait dimensions can be remembered by using the acronym OCEAN, in which each of the letters is the first letter of one of the five dimensions of personality [1]. 
As described by [1] these personalities have the following characteristics; Openness can best be described as a person's willingness to try new things and be open to new experiences. People who try to maintain the status quo and who don't like to change things would score less on openness.

Conscientiousness refers to a person's organization and motivation, with people who score high in the dimension being those who are careful about being in places on time and careful with belongings as well. Someone scoring low on this dimension, for example, might always be late to important social events or borrow belongings and fail to return them or return in poor coordination.

Extraversion is a term first used by Carl Jung, who believed that all people could be divided into two personality types: extraverts and introverts. Extraverts are outgoing and sociable, whereas introverts are more solitary and dislike being the center of attention.

Agreeableness refers to the basic emotional style of a person, who may be easygoing, friendly and pleasant (at the high end of the scale) or grumpy, crabby and hard to get along with (at the low end).

Neuroticism refers to emotional instability or stability. People who are excessively worried, overanxious and moody would score high on this dimension, whereas those who are more even-tempered and calm could score low.

\subsection{Meaning and Factors Affecting Academic Achievement}

\subsubsection{Meaning of Academic Achievement}

Academic achievement also defined as something you do and or achieve at school, college or universities- in class, laboratory, library or fieldwork [3]. This means academic achievement is the extent to which learners of any grade level is profiting from the given instruction in a given area of discipline.

Academic achievement shows the teachers where areas of improvement were needed and it may use as concert evidence of it. Performance results allow students to be ranked and sorted on a scale that is numerically obvious, minimizing complaints by holding teachers and institutions accountable for the components of every grade [17].

\subsubsection{Factors Affecting Academic Achievement}

Two significant, interdependent elements contribute to the performance of students. As Hojat M, Erdmann JB, Gonnella JS. Cited in [2] the first element involves a group of cognitive capabilities that usually manifest themselves as intellectual abilities, such as achievement on exams requiring recall of factual knowledge and assessment of declarative information. The second element, frequently identified under the rubric of non-cognitive or personal qualities, incorporates components including personality attributes, behavior, values, interests, and other personal qualifications.

As Kroeger O, Thuesen J, and Rutledge H. cited in [2] the significance of understanding one's individual personality is crucial to performance in study, at work, at home and to one's communication with others and also the relationships in the workplace, at school and at home, play a key role in our achievement in form of marks and satisfaction. On the other hand, interpersonal dynamics and characteristics vary within relationships, turning a blind eye to personality patterns can cause disagreement and disappointment that is might lead to considerable influence on our academic accomplishment.

Agreeableness is positively related to academic performance [21]. Another dimension of personality, Openness is the degree of intellectual curiosity, creativity and a reference for novelty and variety. There are various studies which have found the positive association between openness and academic achievement and Conscientiousness is a tendency to show self-discipline, act dutifully and aim for achievement amidst various challenges. It was regarded as the more imported factor which has a vital role in achieving academic success [21].

Therefore, regardless of intelligence, socio-economic status, and social factors, interest, attitude, engagement, the desire to achievement with willingness to study constantly can also be the secret behind academic success. Apparently, good grade is related with personality characteristics of need to achievement academically. Individuals with high need for achievement doing achievement related activities to become successful in his or her academic work as [11].

Perceived as academic competence is determining factors for academic success. As Workneh cited in [11]. Students who perceive themselves as academically competent tend to display high level of task engagement that leads them to achieve academically. Hence, student's perception of himself, his ability, his needs to achieve and behaving in socially appropriate way such as being cooperative and helpfulness that may result in positive academic interaction with peers and teachers can also contribute for academic achievement [11]. Therefore, achievement is not an easy task. It needs effort, strategies, patience, and persistence in difficult tasks as well as responsibility to achieve at it.

\subsection{The Relationship Between The Big Five Personality Types and Academic Achievement}

In psychology, the Big Five factors of personality can be describe as the five dimensions of personality that is used to describe the human personality. The Big Five personality types are Neuroticism, Extraversion, and Openness to Experience, Agreeableness and Conscientiousness. As [16] conducted a study on the relationship between the Five Big personality Types and academic achievement. The result shows that academic achievement of students' has a strong positive relation with personality traits.

[21] Studied the relationship between Big Five personality types and a measure of work drive to course grade measured by GPA in undergraduate psychology course among 175 students. The correlation analysis was found that there is a positive relationship between Conscientiousness and Openness and GPA in a psychology course. In addition to the above finding the Big Five personality traits, Conscientiousness implements more effective in which allow them to succeed academically. This finding matches the work 
of [23].

The Big Five factors of personality Extraversion, Conscientiousness and Openness to Experience are most relevant in educational setting and each of these factors were positively correlated with academic success and contrast to Neuroticism [9]. In relation to the above finding, the combinations of Big Five traits have also been found to predict various educational outcomes. Namely, conscientiousness, agreeableness and openness predict course performance [25].

On the other hand the other Big Five personality traits only weak and inconsistent related to academic achievement. Personality types like neuroticism or emotional instability is negatively associated with academic achievement [5].

[15] Undertook the study of the personality factors of high and low achievers of elementary level students. The sample for the study was 100 (50 high achievers and 50 low achievers) who were selected randomly from one educational zone. The results revealed that high achievers were reserved, detached, aloof, critical, stiff, more intelligent and high achievers were found to be emotionally less stable, mature and faced reality while as low achievers were emotionally unstable and affected by feelings.

\section{Methods and Material}

The study employed quantitative approach of correlational design to conduct the study. The approach was selected for its appropriateness to the nature of the study. The basic objective of correlation design is to explain and predict the association between variables. [20] Held similar position by stating, the purpose of correlation research is to measure two or more variables and examine whether there are relationships among the variables. In addition to this, [12] stated that the major purpose of correlational research is to clarify our understanding of important phenomena by identifying relationship among variables.

Description of the study area: Oromia is the largest National Regional State in the Federal Democratic Republic of Ethiopia. The region lies between $3^{\circ} 40^{\prime}$ and $10^{\circ} 35^{\prime}$ North $34^{0} 05^{\prime}$ to $43^{0} 11^{\prime}$ East and covers a geographic area of about 364,606 square kilometers [4]

Population of the study: In Oromia there are 12 Colleges of Teachers Education. In order to manage the study four colleges of teachers education was selected, namely Sebeta, Nekemte, Adola and Fiche Teachers' Education College. In the selected CTE there are 2291 male and 2734 female students. The total population of the study was 5025 from year one to year three of regular students. The study used primary and secondary sources of data. Students are served as primary and record sheet of student's grade point served as secondary source.

Sampling methods and procedures: Simple random sampling method was used to select four CTE namely, SSNEC, NTEC, ATEC and FTEC. The selected colleges were representatives of the others. To include student from each department as a sample of study, stratified random sampling techniques was used first. After stratified random sampling techniques, 160 male students and 197 female students totally 357 students were selected using simple random sampling techniques and the selected students are the representatives of the population. The adapted questionnaire is coded, administered and gathered from sample of the study, analysis was made.

Sample size of the study: The total population was 5025 students. From the total population 357 students (160 male and 197 female) was selected as sample of the study for responding the adapted questionnaire. These respondents were selected by using [24] sampling formula.

Table 1. Population and sample of the study.

\begin{tabular}{|c|c|c|c|c|c|c|c|}
\hline \multirow{2}{*}{$\begin{array}{l}\text { Name of } \\
\text { Colleges }\end{array}$} & \multirow{2}{*}{$\begin{array}{l}\text { Years of } \\
\text { Study }\end{array}$} & \multicolumn{3}{|c|}{ Population } & \multicolumn{3}{|c|}{ Sample } \\
\hline & & Male & Female & Total & Male & Female & Total \\
\hline \multirow{4}{*}{ Adola } & $1^{\text {st }}$ & 173 & 202 & 375 & 12 & 14 & 26 \\
\hline & $2^{\text {nd }}$ & 148 & 176 & 324 & 10 & 13 & 23 \\
\hline & $3^{\text {rd }}$ & 170 & 115 & 285 & 12 & 8 & 20 \\
\hline & Total & 491 & 493 & 987 & 34 & 35 & 69 \\
\hline \multirow{4}{*}{ Fiche } & $1^{\text {st }}$ & 143 & 149 & 292 & 10 & 11 & 21 \\
\hline & $2^{\text {nd }}$ & 138 & 160 & 298 & 10 & 12 & 22 \\
\hline & $3^{\text {rd }}$ & 118 & 166 & 284 & 8 & 12 & 20 \\
\hline & Total & 399 & 475 & 874 & 28 & 35 & 63 \\
\hline \multirow{4}{*}{ Nekemte } & $1^{\text {st }}$ & 315 & 461 & 776 & 22 & 33 & 55 \\
\hline & $2^{\text {nd }}$ & 200 & 263 & 563 & 14 & 19 & 33 \\
\hline & $3^{\text {rd }}$ & 329 & 389 & 718 & 23 & 28 & 51 \\
\hline & Total & 844 & 1113 & 1957 & 59 & 80 & 139 \\
\hline \multirow{4}{*}{ Sebeta } & $1^{\mathrm{st}}$ & 183 & 207 & 390 & 13 & 15 & 28 \\
\hline & $2^{\text {nd }}$ & 219 & 272 & 491 & 15 & 20 & 35 \\
\hline & $3^{\text {rd }}$ & 155 & 174 & 329 & 11 & 12 & 23 \\
\hline & Total & 557 & 653 & 1210 & 39 & 47 & 86 \\
\hline Grand Total & & 2291 & 2734 & 5025 & 160 & 197 & 357 \\
\hline
\end{tabular}

Instrument of the study: The researcher was used 44 items standardized questionnaires known as Big Five Inventory (BFI) constructed by John, Donahue, and Kentle as cited [14] for collected data from the sample of the study. The questionnaire was adapted in order to cultural specific for gathering relevant data to measure Personality types of 
students. The instrument has 5- point Likert scale that ranges from 1 (strongly disagree) to 5 (strongly agree). The adapted instrument have two parts, the first part consists demographic characteristic of respondents and the second part consists self-reports of students about their personality's type. This part contained five sections, each of the big five traits under review. These are Extraversion, Agreeableness, Conscientiousness, Neuroticism and Open to experience, with each containing $10,9,9,8$, and 8 items respectively and making 44 items. Cronbach's alphas were used to estimate reliability of the inventory. The standard Reliability coefficient of the instrument is from .75 to .90 and average above .80 [14]. To measure students' academic achievement first semester of 2015/16 grade reports of students was assessed from college registrars. The code gives for grade $2.00-2.49$ is $1,2.50-2.99$ is 2,3.003.49. is 3 and 3.5-4.00 is 4. Most of the researcher around the world used the GPA to measures students' academic performance [23]. The researcher ensured that adequate modifications were made on some of the items adapted to suit the present study. This was done by simplifying some of the words used without necessarily distorting the meaning, for instance 'Is depressed, blue' was modified as 'I feel very unhappy most times'; and 'Is inventive' was modified as 'I like to create and design new things' etc.

Variables of the study: Independent Variables of the study were the Big Five Personality types: Neuroticism, Extraversion, Openness to Experience, Agreeableness and Conscientiousness and dependent Variable of the study was academic achievement of students' as measured by GPA of first semester of 2015/16 year.

Pilot study: To ensure the reliability of the adapted instrument 18 male and 16 female students was selected from Sebeta Special Need Teachers' Education Colleges. The internal reliability coefficient was calculated at $0.82,0.79$, $0.90,0.81$ and 0.85 for $\mathrm{E}, \mathrm{A}, \mathrm{C}, \mathrm{N}$ and $\mathrm{O}$ for each of personality types respectively. The validity of the adapted instrument was estimate by 4 lecturers of the colleges from department of psychology with personal report form and their observation evaluation. Academic achievement was measured by student's GPA of the year 2015/2016 first semester was taken from students registrars.

Methods of Data Analysis: The data collected from sample of study was coded and entered into the computer for analysis using SPSS program version 20. The response of the participants and their semester average score as measured by GPA was analyzed. In order to describe the demographic characteristics of respondents, descriptive statistic of frequency and percentage was used. To determine the extent of relationships between students' personality type and their academic achievement, Pearson product moment correlation coefficient was calculated. To identify the more predictor of students' personality types on their academic achievement and also investigate the aggregate influence of students' personality types on their academic achievement, multiple regressions was used.

\section{Results}

\subsection{Characteristics of the Respondents}

The demographic characteristics of respondents addressed in this paper were gender, age, program of study and years of studies in their colleges. These characteristics are presented as follows.

Table 2. Background of the Respondents.

\begin{tabular}{llll}
\hline SN & Variables & Frequency & Percent \\
\hline \multirow{4}{*}{1} & Sex & & \\
& Male & 160 & 44.48 \\
& Female & 197 & 55.52 \\
& Total & 357 & 100.0 \\
& Age & & \\
& 16 & 11 & 3.71 \\
& 17 & 63 & 17.5 \\
& 18 & 108 & 29.44 \\
& 19 & 95 & 26.33 \\
& 20 & 52 & 14.81 \\
& 21 and above & 28 & 8.21 \\
& Total & 357 & 100.00 \\
& Study year & & \\
& First year & 130 & 36.47 \\
& Second year & 113 & 31.60 \\
& Third year & 114 & 31.93 \\
& Total & 357 & 100.00 \\
\hline
\end{tabular}

As it is indicated in the above table, among 357 respondents $160(44.48 \%)$ of them are male and the remaining 197 (55.52\%) are females. This shows that, there are a higher proportion of female students than male students in the study area. Cornering age of students, most of the children who had been included in survey questionnaire are 18 years old that comprises $29.44 \%$ of the total respondents. $3.7 \%$ of students from total respondents were belongs to 16 years of age. $17.5 \%$ and $26.33 \%$ of respondents were belongs to the age of 17 and 19 respectively. At the end $14.81 \%$ and $8.21 \%$ of students from the total respondents were belongs to

20 and 21 above years of age respectively. This indicates that, there are a higher proportion of students with 18 years age and 16 years age were low proportion in the study area. Regarding to students year of study, out of 357 more of respondents $130(36.47 \%)$ were first year students, 113 $(31.6 \%)$ of students were second year and 114 (31.93\%) of them were stay three year in a colleges. This shows that, there are a higher proportion of students from first year in the study area (see 2)

\subsection{The Relationship Between Personality types and Students'Academic Achievement}

The Pearson correlation coefficient was computed to determine the degree, strength and directions of association between personality types and academic achievement of students' in Oromia Colleges of teachers Education. 
Table 3. The correlation between personality types and Academic Achievement $N=357$.

\begin{tabular}{llllll}
\hline Variables & $\mathbf{E}$ & $\mathbf{A}$ & $\mathbf{C}$ & $\mathbf{N}$ & $\mathbf{O}$ \\
\hline $\mathrm{E}$ & 1 & & & & \\
$\mathrm{~A}$ & -.257 & 1 & & & \\
$\mathrm{C}$ & -.348 & .057 & 1 & & \\
$\mathrm{~N}$ & -.678 & .076 & .661 & 1 & \\
$\mathrm{O}$ & -.526 & .81 & .556 & .278 & 1 \\
$\mathrm{AA}$ & -.10 & .91 & .85 & -.84 & .87 \\
\hline
\end{tabular}

*correlation is significant at 0.05 level (2-tailed) $\mathrm{r}=$ person correlation coefficient

As the correlation analysis result indicated above on the table 3, agreeableness students personality types had strongly positive relationship with students' academic achievement having a correlation coefficient of $\mathrm{r}=0.91$ at the significance level of $\mathrm{p}<0.05$ ), where $\mathrm{N}=357$. As column three on the above table 3 of correlation analysis indicated Conscientiousness students personality types had strongly positive relationship with students' academic achievement having a correlation coefficient of $r=0.85$ at the significance level of $\mathrm{p}<0.05$ ), where $\mathrm{N}=35$. Similarly the correlation analysis finding indicated that neuroticism students personality types had strongly negative correlation with students' academic achievement having a correlation coefficient of $\mathrm{r}=-0.84$ at the significance level of $\mathrm{p}<0.05$ ), where $\mathrm{N}=357$

Finally the correlation analysis finding indicated that, open to experience students personality types had strongly positive relationship with students' academic achievement having a correlation coefficient of $\mathrm{r}=0.87$ at the significance level of $\mathrm{p}<0.05$ ), where $\mathrm{N}=357$ but extraversion students personality types had negatively low correlated with students' academic achievement having a correlation coefficient of $r=-10$ at the significance level of $\mathrm{p}<0.05$ ), where $\mathrm{N}=357$. This result shows that open to experience, Conscientiousness and agreeableness have strong positive relationship with student's academic achievement but there is strong negative correlation between neuroticism student's personality types and their academic achievement in the study area. However there is negatively low correlation between Extraversion student's personality and their academic achievement in the study area.

\subsection{The impact of Personality Types on Academic Achievement}

Table 4. Standardized multiple regression of personality types on Academic Achievement.

\begin{tabular}{|c|c|c|c|c|c|c|c|c|c|}
\hline \multicolumn{2}{|c|}{ Model } & \multicolumn{2}{|c|}{ Unstandardized Coefficients } & \multirow{2}{*}{$\begin{array}{l}\text { Standardized Coefficients } \\
\text { Beta }\end{array}$} & \multirow[t]{2}{*}{$\mathbf{T}$} & \multirow[t]{2}{*}{ Sig. } & \multirow[t]{2}{*}{$\mathbf{R}$} & \multirow[t]{2}{*}{$\mathbf{R 2}$} & \multirow[t]{2}{*}{ Adjusted R2 } \\
\hline & & $\mathrm{B}$ & Std. Error & & & & & & \\
\hline \multirow[t]{6}{*}{1} & (Constant) & 2.359 & .187 & & 3.861 & .000 & 0.025 & .194 & -0.002 \\
\hline & Extraversion & -0.661 & 0.040 & -.431 & 4.465 & .065 & & & \\
\hline & Agreeableness & .732 & .315 & .859 & 17.062 & .048 & & & \\
\hline & Consciousness & .683 & .036 & .793 & 14.531 & .041 & & & \\
\hline & Neuroticism & -.815 & .046 & -.757 & -6.784 & .049 & & & \\
\hline & Open to experience & .861 & .054 & .897 & 16.818 & .040 & & & \\
\hline
\end{tabular}

a. Predictors: (Constant), Extraversion, Agreeableness, Consciousness, Neuroticism, Open to experience b. Dependent Variable: Academic achievement result

As shows from the above table 4 , all independent variables are statistic significantly related to academic achievement of students' except extraversion because their significant values are less than the significant level $(p<0.05)$. Besides the standardized coefficients beta three variables Open to Experience, Agreeableness and Conscientiousness are positively predict students' academic achievements and relatively open to experience personality types were the more predictor, followed by agreeableness and Conscientiousness personality type at standardized Beta $(.897, .856$, and .793) respectively. On the other hand the two independent variables Neuroticism and Extraversion personality types were negatively predict the independent variable students GPA at standardized Beta (-.757 and -.431$)$.

In the model summary box of the above table, R2 was found to be 0.194 . This result indicated that the combined effects of personality types predicted $19.4 \%$ of students' academic achievements described by GPA. This means the remaining $80.6 \%$ accounted by other variables that not conducted in the present study.

\section{Discussion}

\subsection{Demographic Characteristics of Respondents}

According to table 3 there are higher proportion of female students than male students in the study area. Regarding the respondents age level, higher proportion of students with 18 years age and low proportion of students were with 16 years age in the study area. Additional in respect to student's year of study, there are a higher proportion of students from first year in the study area.

\subsection{The Relationship Between Students' Personality Types and Their Academic Achievement}

In this studies the researcher use the Big Five Personality Factors as independent variables (predictors) and academic achievement of students indicated by GPA as dependent variables. Those Big Five Personality factors are known by OCEAN.

The investigation digs out that how extraversion types of 
students relate to academic achievements of students in Oromia Colleges of Teachers' Education. As presented in table 3 almost there is negatively low correlation or nearly no correlation between students' personality types and their academic achievement in the study area. This finding is supported with the study of [7] that Extraversion types of psychological person have no relationship with academic achievement of students and there is no statistically significant difference between extraversion types of students and their academic achievements. As the study of [7] found that found that extraverted students engaged more in social and impulsive activities, and spent few hours a day in studying.

In this study, the researcher finds out how extent do agreeableness personality types correlate with students' academic achievement? As presented in table 3 there is statistically significant difference between agreeableness personality type and academic achievement and there is strong positive correlation between independent variable (agreeableness) and academic achievement of students in the study area. The finding describe that agreeableness have direct relationship with academic achievement and it predict the academic achievements of students of Oromia Colleges of Teachers' Education. My finding is similar with the study of [19] academic performance is positively associated with agreeableness and there is statistically significant relationship between the students' personality trait Agreeableness and their academic achievement.

In table 3 the finding shows that there is statistically significant and there is strong positive correlation between the predictor variable Conscientiousness personality types and academic achievement of students in Oromia Colleges of Teachers' Education. This implies that Conscientiousness personality types predict academic achievement of students and strong positive correlation with students' academic achievements i.e. students those described by high Conscientiousness were excellent achiever in academic performance indicated by GPA and low Conscientiousness (lack of direction) personality types are associated with poor achiever academically. According to [28] that describes the correlation of the two variables as there is significant relationship between the students' personality trait "Conscientiousness" and their academic achievement. [25] support this finding that Conscientiousness types of students predict academic achievement of students and correlate positively with academic achievement of students.

In table 3 the finding shows that there is statistically significant and there is strong negative correlation between the predictor variable neuroticism and academic achievement of students in Oromia colleges of Teachers' Education. This implies that high neuroticism personality types of students are associated with poor academic achievement that indicated by GPA but low neuroticism personality types of students (emotional stability) were an excellent academic achiever. This finding also supported with [5] that neuroticism or emotional instability is negatively associated with academic achievement.

In the table three and four the finding shows that there is statistically significant and there is strong positive correlation between the predictor variable open to experience and academic achievement of students in Oromia Colleges of Teachers' Education. This implies that high open to experience personality types of students were associated with high academic achievement indicated by GPA and the reverse is true. [6] Strength this finding that open to experience is positively associated with academic achievement and significant predictor of academic achievement. [25] Describe that open to experience types of students predict academic achievements of students and positively correlate with academic achievement.

\section{Conclusion}

In examining the correlation between personality types Extraversion, Agreeableness, Conscientiousness, Neuroticism, Open to experience and academic achievements that measured by GPA, based on the finding the following implications were concluded.

The profile of students at the study area shows that the proportions of female that have joined CTE were higher than male. From this, it is possible to conclude that there are higher numbers of female students in Oromia Colleges Teachers Education.

The finding also shows that more of the respondent's age was 18 years old. This implies that the trainers/students in CTE are enough adolescence. They are active resource as a human power for the study area.

In this study the finding shown that, there is significant relationship between independent variables and academic achievement except extraversion types of personality. Therefore, it is found here that, high Agreeableness, high Conscientiousness and high Open to experience personality types were correlated with students' of high academic achiever. And also open to experience personality types is more predictor of academic achievements and followed by Conscientiousness and Agreeableness. On the other hands Antagonism, lacks of direction and close to experience students' personality types are low in their academic in Oromia Colleges of Teachers' Education.

The grade point average of students those known by extraversion types of personality have not a relationship. On the opposite dimension Introversion students may have a correlation with their academic activities and on their point that measure by GPA.

Students those have neuroticism types of personality are low achiever in their academic issue. and an emotional stability, type of personality is significantly correlated with academic achievements of students. Finally, the finding indicated that the aggregation results of personality types were significantly correlated with students' academic achievement in Oromia Colleges of Teachers' Education.

\section{Recommendations}

The following recommendations can be forwarded based on the result of the study. 
i. The result of this research shows Academic achievement can be determined by personality type OCEAN except extraversion. Therefore lecturers of CTE in Oromia region should not assume that students are a homogeneous group and may need different types of psychological techniques in order to perform well. Knowing the personality profiles of students, they can be more helpful to each student.

ii. Identify their students in accordance to their personalities especially those students that have high Agreeableness, Conscientiousness, Open to experience personality encourage them in order to shine out their talent, this help them to perform better in their academic. Group assignments requiring cooperation work, so the lecturers should be encouraged students those extrovert in nature to be give attention while in discussion rather than more speaking and those isolated students as introvert should be participated as a leaders to improve their communication skill and the others. The counseling service should be strong and active in Oromia CTE especially for students with neuroticism and also for all students' personality types.

iii. Oromia Education Bureau should give attention for counseling service in CTE by allocating the necessary budget, assigning counselors and make a relationship with counseling centers in the country like hospitals. Seminars, training, and workshop for lecturers and colleges Deans on the issue of personality types and their impact on students' academic achievement should be prepared time to time. In the finding, male students are greater than female students; therefore the Bureau should be balance the proportion by preparing the necessary guideline in line with others rule and regulation of the country and the world.

iv. Further researches may be conducted at higher level and on a larger number of participants so that it may be found out whether there exist a significant relationship between personality types and students' academic achievement.

\section{References}

[1] Aemero Asmamaw et al (2019). General psychology module. Federal Democratic Republic of Ethiopia Ministry of Science and Higher Education. Unpublished.

[2] Alshehri KA. et al (2018). The relationship between personality type and the academic achievement of medical students in a Saudi medical school. Int. journal of Community Med Public Health: 5: 3205-11.

[3] Annie W. (1996) Achievement and Ability Tests - Definition of the Domain, Educational Measurement. University Press of America, pp. 2-5.

[4] BoFEDO (2010). Finance and Economic Development Bureau of Oromia Regional Government- GIS Data Base. Unpublished.

[5] Chomoro-Premuzic T. \& Furnham A. (2003). Personality predicts academic performance: Evidence from two longitudinal university samples. Journal of Research in Personality, pp 319-338.

[6] Chomoro-Premuzic T. \& Furnham A. (2006). Personality traits and academic performance. European Journal of Personality, pp 237-250.

[7] Chowdhury M. (2006) Students' personality traits and academic performance: A Five Factors Model Perspective. volume 9 number 3 Network.

[8] Costa, T \& McCrae, R. R (1992). Normal personality assessment in clinical practice: The NEO Personality Inventory. Psychological Assessment, pp 5-13.

[9] De Raad B. \& Schouwenburg C. (1996). Personality in learning and education: a review. European Journal of Personality, pp 303-336.

[10] Digman J. M. (1990). Personality structure: Emergence of the Five-factor model. Annual Review of Psychology, pp 417440.

[11] Dinka B. (2013). Personality Type And Learning styles As Correlates Of Academic Performance of High School. Unpublished M. A. Thesis, A. A. U.

[12] Fraenkel J. \& Wallen N. (2009). How to Design and Evaluate Research in Education. (10th ed.). New York: The McGrrawHill EnglerCompanies Inc.

[13] Goldberg L. R. (1992). The structure of phenotypic personality traits. American Psychologist 48 pp 26-34.

[14] John, O. P., \& Srivastava, S. (1999). The Big-Five trait taxonomy: History, measurement, and Theoretical perspectives. Theory and research (Vol. 2), pp. 102-138). New York: Guilford Press.

[15] Khan. M. A. \& Bhat A. G. (2008). Personality Profiles of High and Low Achievers. Insight: The Journal of Applied Research in Education. 14 (1), pp 28-35.

[16] Koning B. B., Loyens S. M.., Riker R. M.., Smeets G. \&Molen H. T. (2012). Generation Psychology: Student Characteristics and Academic Achievement in a Three-year Problem-based Learning Bachelor Program. Learning and Individual Differences 22: pp 313-323.

[17] Kour P. \& Sharma P. (2013). International Journal of Innovative Research and Development. ISSN: 0211-2278, Jammu, India.

[18] Kuncel N. R., Crede M., \& Thomas L. L. (2005). The validity of self-reported grade point averages, class ranks, and test scores: A Meta-analysis and review of the literature. Review of Educational Research, 75 (1), pp 63-82.

[19] Laidra K., Pullmann H., \&'Allik J. (2007). Personality and intelligence as predictors of academic achievement. Acrosssectional study from elementary to secondary school. Personality and Individual Differences, pp 1-11.

[20] Lodico M., Spaulding D. \& Voegtle K. (2010). Methods in Educational Research: From Theory to Practice. (2nd ed.). USA: John Wiley \& Sons Inc.

[21] Lounsbury et al (2003). The development of a big five adolescent personality scale. Psycho educational assessment volume (21) pp 111-133.

[22] McCrae, R. \& John, O. P. (1992). An introduction on five factor model and its implications. Journal of Personality, pp 169-175.

[23] McKenzie (1989). Neuroticism and academic achievement: The Five factor. Personality and Individual Differences, pp 509- 515. 
[24] Morgan D. W \& KrejcieR. V (1970) Educational and Psychological Measurement: University of Minnesota, Doluth.

[25] Paunonen S. V. \& Ashton M. C. (2001). Big Five Predictors of Academic Achievement. Journal of Research in Personality, pp 78-90.

[26] Pressley et al (1997). Some of the reasons why preparing for exams is so hard: What can be done to make it easier? Educational Psychology Review, 9 (1), 1-38.
[27] S. Hafiz (2016) Personality as Predictors of Academic Achievement among University Students, International Journal of Indian Psychology, Volume 3, Issue 3, No. 6, DIP: 18.01.100/20160303.

[28] Soraya H., Elaheh H. \& Masoud G. (2011) Department of Educational Psychology and Counseling. University of Tehran, Tehran, Iran, pp 836-845. 